\title{
A study of the weldability of gamma prime hardened superalloys
}

\author{
Alexander Schnell ${ }^{1, a}$, Matthias Hoebel ${ }^{2, b}$, Jeff Samuleson ${ }^{3, c}$ \\ ${ }^{1}$ ALSTOM Power Arabia FZE, Jebel Ali Freezone, Dubai, UAE \\ ${ }^{2,3}$ ALSTOM Power Switzerland, 5242 Birr, Zentralstrasse 40 \\ a alexander.schnell@power.alstom.com, ${ }^{b}$ matthias.hoebel@power.alstom.com, \\ c jeff.samuelson@power.alstom.com
}

Key words: welding, GTAW, Laser welding, superalloy, repair, turbine

\begin{abstract}
Fusion repair processes such as gas tungsten arc welding (GTAW) and laser welding have been introduced for repairing turbine parts made from Ni-based superalloy materials. The weld-repair of turbine parts is well established, however, the inherent susceptibility of $\gamma^{\prime}$ hardened superalloys to weld cracking remains an issue and has resulted in repair limitations for highly loaded areas of turbine parts. This study presents a view of the weldability of superalloys taking both, the impact of the weld process and the weld filler selection into consideration. This comprises the interpretation of specific process parameters into physical parameters controlling the weldability and cracking sensitivity such as thermal gradient in the weld pool and solidification speed. Alloy specific parameters of the weld filler material, such as melting point and solidification interval are studied and set in correlation with the solidification parameters during welding.
\end{abstract}

\section{Introduction}

Nickel based superalloys are widely used in the gas turbine industry as they exhibit excellent high temperature properties and strength primarily due to precipitation hardening by the $\mathrm{Ni}_{3} \mathrm{Al} \gamma^{\prime}$ phase. However, $\gamma^{\prime}$ precipitation-strengthened alloys are very difficult to weld in a crack-free manner due to their inherent susceptibility to heat affected zone (HAZ) cracking during welding and during post-weld heat treatment $[1,2,3]$. Despite the difficulties regarding crack-free welding of superalloys, welding is the most essential joining and repair process for turbine parts [4]. This applies to the reconditioning of ex-service turbine parts and also to the weld-repair of new parts in order to improve the casting yield. Hot section parts are too costly to be replaced after one service interval or to be scraped during new-make because of relatively small casting defects.

\section{Parameters influencing weldability of superalloys}

The weldability, i.e. the susceptibility to cracking of $\gamma^{\prime}$ strengthened superalloys is a function of various parameters, that can be summarized and categorized as follows:

Base material: responds to local welding conditions

Heat treatment, microstructure, residual stresses, ductility, thermal diffusivity

Impurity level of trace elements with $\mathrm{k}<<1(\mathrm{~S}, \mathrm{P})$, master melt, i.e. batch dependent

casting micro segregations, size and amount of eutectics

grain size, especially related to the local wall thickness, i.e. grains per volume

Weld filler: defines solidification behavior of weld pool

huge variety of filler material, mainly dependent on welding process and application

melting point, solidification interval, eutectic fraction, ductility 
Geometry of Part: defines the local heat flux conditions during welding

- local wall-thickness, melt pool volume and heat dissipation

- accessibility for welding, i.e. stability of weld pool

- surface condition, presence of oxide layer (in particular relevant for laser welding)

- welding strategy, impacts build up/control of residual stresses

Welding process: defines heat source and weld-pool cooling characteristics

- huge variety of welding processes and related parameters

- manual welding: skill of welder/operator incl. part preparation

Various combinations of these parameters can lead to different cracking mechanisms such as

- solidification (hot) cracking

- constitutional liquation cracking along grain boundaries

- sub-solidus / ductility dip cracking and

- strain age cracking during post weld HT, see $[1,2,3]$ for details.

The huge variety of influencing parameters makes it difficult to clearly benchmark the weldability of a particular superalloy. It is also problematic to assess the weldability of a part/location or the quality performance of a process, as it is difficult to clearly identify the main reason for cracking. In order to demonstrate the complexity of superalloy weldability issue, two different industrial applications of turbine part weld repair are presented, namely standard manual GTAW and an advanced laser welding process.

\section{Process charts for GTAW and Laser welding}

Process windows for crack-free welding can be plotted in gradient $[K / m]$ versus solidification speed $[\mathrm{m} / \mathrm{s}]$ charts, see Fig. 1 . The specific process parameters are translated into a thermal gradient $G$ present in the weld pool and a solidification speed $v$ of the weld filler. Filler specific parameters, in particular the solidification interval $\left(\Delta T_{0}\right)$ can be put in correlation with the solidification parameters $G$ and $v$ via the equation $G / v \approx \Delta T_{0} / D_{s}$, where $D_{s}$ is mass diffusion in the solid. According to this equation, weld fillers with a small interval $\Delta T_{0}$ are desired, i.e. increase the process window.
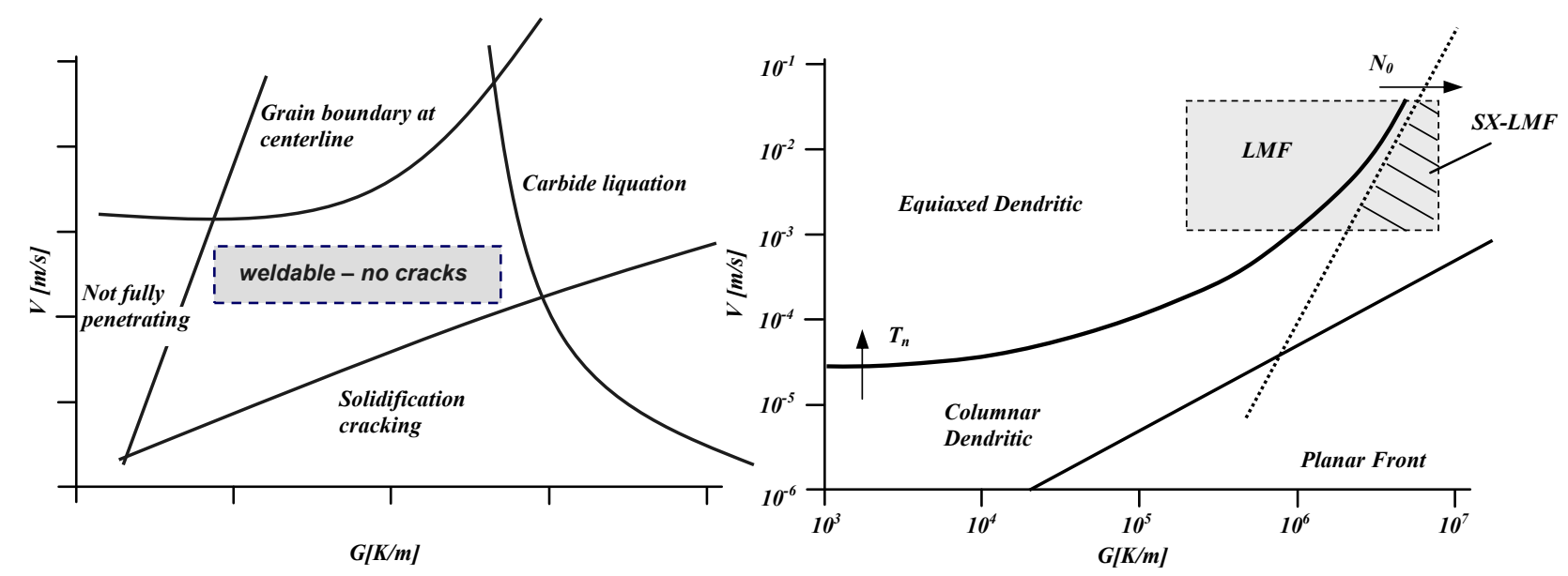

Fig.1: Process chart showing the weldable window for (left) GTAW [12] and (right) for SX-LMF as function of $\mathrm{G} / \mathrm{v}$ and material specific parameters as $\mathrm{N}_{0}$ (nucleation site density) and Tn (undercooling of nucleation)

[11]. 
Filler wires for GTAW are typically made from solid solution and carbide strengthened Nickel based alloys. These materials offer good weldability due their inherent ductility. Compared to the $\gamma^{\prime}$ strengthened base material, ductile weld fillers exhibit good oxidation resistance and LCF/TMF lifetime, but the creep properties are significantly lower. This of course limits the application of the manual GTAW to locations for which the thermal and mechanical loadings are exactly known. The manufacturing of $\gamma^{\prime}$-strengthened weld fillers is very cost intensive so that their mainly used in the case of high mechanical integrity requirements. Also the cracking sensitivity of $\gamma^{\prime}$-strengthened fillers is inherently high, therefore requiring pre-heating of the part during welding $\left(>\sim 900^{\circ} \mathrm{C}\right)$, which in turn complexes the general simple manual GTAW process. In contrast, for laser welding any metallic material that is available in powder form can be injected into the Laser beam offering more freedom regarding alloy design.

\section{Manual GTAW repair of Gas Turbine parts}

Turbine blades and vanes tend to crack due to the severe thermal loadings and are therefore repaired during standard overhaul cycles. The cracked material is first removed by grinding and then these ground regions are re-filled by manual welding. In an experimental study ex-service and rejuvenation heat-treated IN738LC material has been weld-repaired by manual GTAW and the heat input i.e. high frequency mode (on/off) and current (high/low) have been varied from sub-optimum to optimum. The welding speed impacts the heat input but is difficult to control for a manual process. However, torch speed is among other parameters such as weld pool stability and cooling conditions reflected in the individual skills of the welder. After welding, the sections have been ground, post-weld heat-treated and checked for cracks using fluorescent penetrate inspection (FPI).

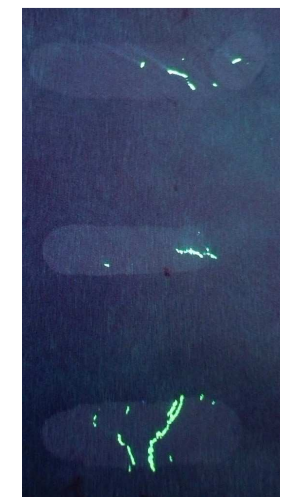

Trainee welder

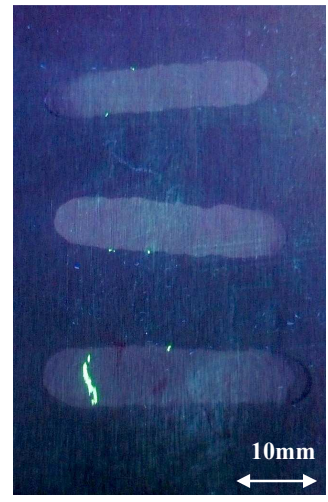

Well-trained welder

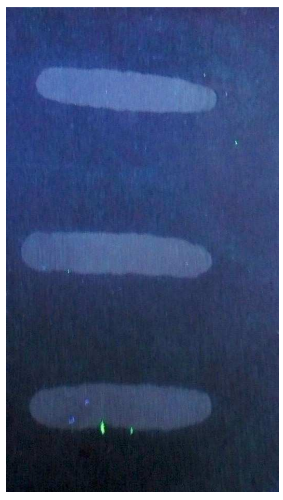

Top-trained welder
Optimum parameters

HF on + low current

Standard parameters

HF off + low current

sub-optimum parameters

HF off + high current

Fig.2: FPI results of manual GTAW welded IN738LC material, ground and post-weld heat-treated. The image matrix shows the impact of process parameters such as high frequency (HF) and welding current versus the individual welder skills.

The study shows that a low heat input results in crack-free welds or in some small surface breaking cracks $(<0.5 \mathrm{~mm})$ at the fusion line only. In case that the heat input is increased, crack size increases drastically and cracks also appear in the weld metal itself (defect size $>5 \mathrm{~mm}$ ), see also [5]. The study has been repeated using two different ductile weld fillers: filler $a$ with $\Delta T_{0}=60 \mathrm{~K}$ and filler $b$ with $\Delta T_{0}<30 K$. Despite the different solidification interval, the overall result as shown in Fig. 2 is not changing.

Small cracks at the weld/base material interface are typically caused by grain boundary liquation during welding. This has been confirmed by metallurgical investigations. Also observed are several sub-surface cracks at the HAZ. The large cracks in the weld occur during post-weld heat treatment. It can be concluded that strain-age cracking can be better avoided by appropriate control of heatinput during welding rather than by a special post weld heat treatment, i.e. fast heating rates, which is hardly applicable for large turbine parts. 
Furthermore, various airfoil sections of different thicknesses and grains sizes have been investigated too. In this case cracking occurs randomly and cannot be attributed to the heat input or the skill of the welder. The main conclusion is that for a thin airfoil section with just a few grains and even locally some mono-grains that expand through the entire wall-thickness will always crack during welding. The inherent cracking susceptibility is explained by large internal stresses that build up between individual grains with different orientations. Consequently, it seems that the solidification properties of the weld filler play a minor role for the crack-free welding using the manual GTWA process.

\section{Laser Melting Forming (LMF) - applied to the repair SX blade tips}

LMF is a fully automated process whereby a filler material is deposited on a substrate by local high power laser melting. The high intensity of the laser beam forms a melt pool into which the new filler material is continuously added. It is thus possible to rebuild lost material onto an existing substrate layer by layer [6]. If the injected filler material has the same composition as the substrate, solidification begins by epitaxial growth, i.e. growth of the solid occurs without nucleation as the nucleation undercooling $\Delta T_{n}$ is zero. The latent heat of solidification is evacuated by conduction in the solid and the temperature gradient is, at least locally, positive. Also, the laser treated material will have the same crystallographic orientation as the substrate if growth remains columnar during the whole solidification process and thus the so-called columnar to equiaxed transition (CET) is avoided. However, when the filler alloy has a different composition to the substrate, epitaxial and crack free growth may be impossible due to nucleation and growth of different phases [7]. For the repair of worn SX turbine blade tips, the usage of a high-temperature oxidation resistant $\gamma / \beta$ MCrAlY coating material is desired. The influence of various filler composition on solidification behavior has been studied. A new, proprietary filler alloy has been developed that is particularly well adapted for laser metal forming of SX blade tips. The software package Thermo-Calc [8,9] was used to calculate the solidification behavior and phase diagrams of the alloy.
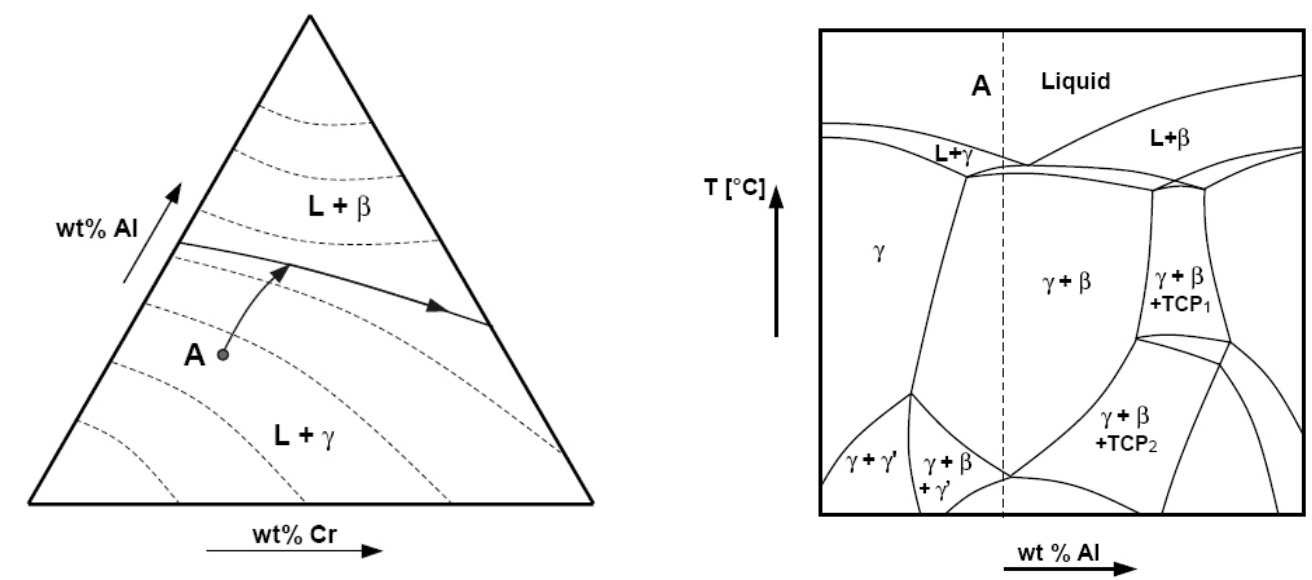

Fig.3: Calculated solidification path (left) and quasi-binary Ni-Al phase diagram (right) of modeled $\gamma / \beta$ MCrAlY coating. Point A and Line A represent the composition of the tailored filler alloy, which results in the required $\gamma$ dendrite growth during solidification.

As a basic rule, the following criteria should be met in order to guarantee the crack-free SX deposition of filler material on SX superalloys [6]:

The filler material should have a composition such that the phase that solidifies first during the LMF process is of the same lattice type as the parent material in order to guarantee epitaxial growth. This requirement restricts the chemical composition of $\gamma / \beta$ - MCrAlY coatings for SX deposition on superalloys, esp. in Al content, see Fig.3

A small solidification interval increases the SX LMF process window because the risk for the formation of hot tearing cracks is reduced. The concentration of elements, which widen the solidification interval of the filler material should be kept low. 
The crystallographic orientation of the parent metal has a significant influence on the solidification behavior of the deposit. As the orientation changes along the blade surface, process parameters have to be adapted to the local conditions on the blade.

In order to achieve SX and crack-free solidification of the deposited material specific process parameters have to be met and high temperature gradients to be created in the melt pool. During Laser cladding, the high energy density of the beam leads to high temperature gradients $\left(G \sim 10^{5}-10^{7}\right.$ $\mathrm{K} / \mathrm{m}$ ) and laser beam velocities (resulting in a solidification velocity, v) are generally in the range of 1 to $50 \mathrm{~mm} / \mathrm{s}$. Under these conditions, the solidification morphology for nickel-base alloys is mainly dendritic, which is the prerequisite for crack-free and SX deposition.

It has been shown that the breakdown of the dendritic growth, i.e. the columnar to equiaxed transition can be described by a universal criterion $G^{n} / v>K$, where $K$ and $n$ are alloy inherent parameters which are functions of the nuclei density and the dendritic growth kinetics of the alloy. This criterion defines the solidification conditions necessary to achieve crack-free and SX LMF, namely a sufficiently high temperature gradient $G$ and/or low solidification velocity. This can be illustrated in processing charts as already outlined in Fig.1 (right) [11].

LMF of the new MCrAlY alloy was performed on the entire tip of a fully heat-treated high pressure turbine blade made from MK4 material, a proprietary SX superalloy, see Fig.4. Laser treatment was carried out using a ROFIN DF012HQ high power diode laser. The continuous wave (CW) laser power is delivered through a flexible optical fiber, which is attached to a coaxial laser/powder head.
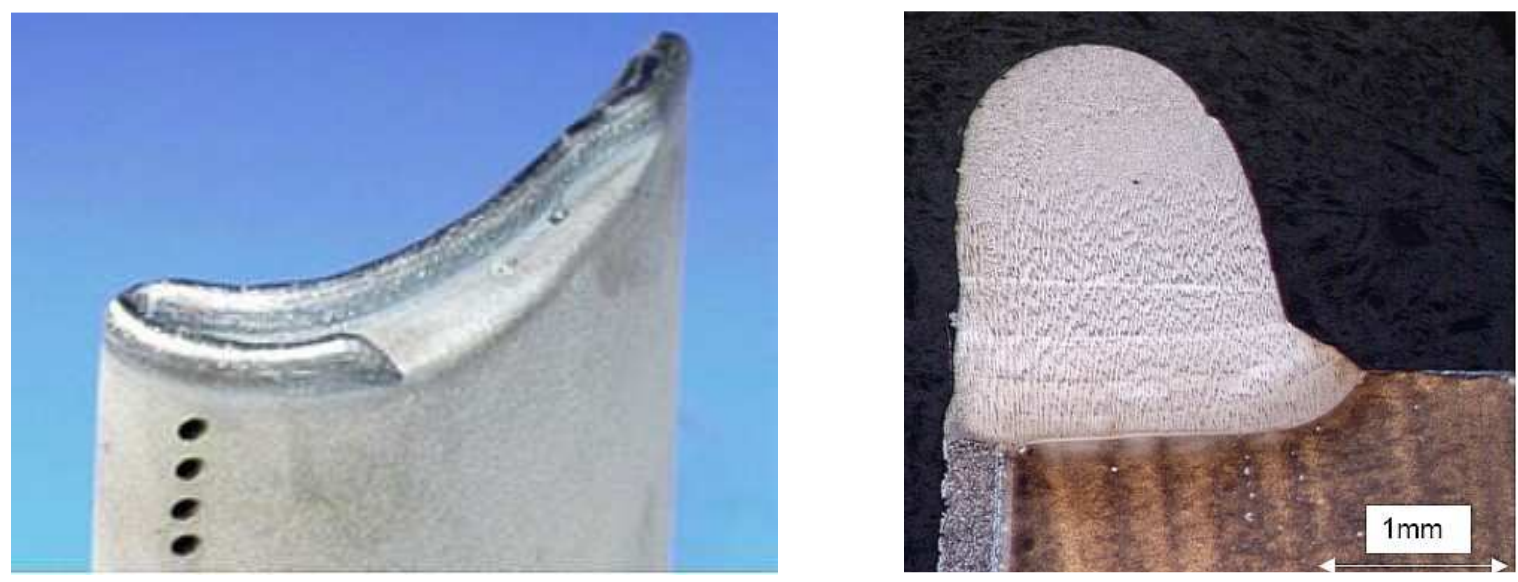

Fig.4: (left) LMF welded HP blade, (right) Crosscut through the SX blade tip, which has been repaired by SX-LMF. The multiple individual weld layers are clearly visible.

Several MCrAlY layers have been laser-welded on top of each other (total $2 \mathrm{~mm}$ ) in a crack-free and fully epitaxial (SX) manner. Such high-temperature oxidation resistant blade tip guarantees application in high efficiency turbines with high firing temperatures.

\section{Conclusion}

Two different welding processes applied to $\gamma^{\prime}$ hardened Nickel-based superalloys have been studied, namely manual GTAW and fully automated laser welding. An advanced process such as LMF technology can only be fully exploited by an interdisciplinary approach and by combining know-how of different areas such as material science/design, process control and automation technology. The filler selection (i.e. control of material inherent solidification properties.) is almost equally important for laser welding than process control itself. Depending on the application special solutions can be tailored. Joining by laser welding becomes increasingly important for the realization of novel part manufacturing concepts such modular component design, i.e. the high strength joining of dissimilar materials. 
On the other hand, for the manual GTAW process variations in the filler material are very limited. Filler selection is basically a compromise between filler availability, reasonable crack-free weldability and the inherent properties of the weld filler (ductility), which in return limits the application of the entire process. For manual GTAW mainly the heat input needs to be controlled to avoid cracking during welding and also during post-weld heat treatments.

It has been shown, that the term weldability is not just related to the $\gamma^{\prime}$ fraction of the welded superalloy (i.e. Al and Ti content) as often quoted.

This comparison shows that, for each particular application, the most relevant parameter needs to be identified and controlled to get the optimum welding performance.

\section{Acknowledgement}

The authors would like to acknowledge the extremely fruitful collaboration with Prof. Wilfried Kurz, Dr. Cyrille Bezençon, Dr. Matthias Gäumann from the "Centre pour le traitement des materiaux par laser” (CTML) of the Swiss Federal Institute of Technology Lausanne (EPFL).

\section{References}

[1] K. Banerjee, N.L. Richards, M.C. Chaturvedi: Metall. and Mat Trans A, 36A, July 2005 - 1881

[2] Ojo O.A., Richards N.L. and Chaturvedi, M.C.: Scr. Mater., 2004; 51: 683-688.

[3] Ojo O.A., Richards N.L. and Chaturvedi, M.C.: Metall. and Mat Trans A, Vol. 37 A, Feb. 2006 $-421$

[4] M. Henderson et al: Science and Technology of Welding \& Joining, Volume 9, No 1, February 2004 , pp. 13-21(9)

[5] Dae-Young Kim et al: Journal of Eng. for GT and Power, July 2000, Vol. 122 - 457

[6] M. Hoebel, B. Fehrmann and A. Schnell: PowerGen Europe, Power Generation Conference, Düsseldorf, Germany, (2002)

[7] C. Bezençon, A. Schnell, W. Kurz: Scripta Materialia 49, (2003), pp. 705 - 709.

[8] Thermo-Calc, version M, Thermo-Calc AB, Stockholm Technology Park, Björnnäsvägen 21, SE-113 47 Stockholm, Sweden.

[9] Saunders N, Ni-DATA database, Thermotech Ltd., Surrey Technology Center, The Surrey Research Park, Guildford, Surrey GU2 5YH, UK.

[10] C. Bezençon, J.D. Wagnière, M. Hoebel, A. Schnell, M. Konter ,W. Kurz: Proc. of the $7^{\text {th }}$ Liège Conference (2002), pp. 1503-1511

[11] M. Gaeumann, C. Bezençon, P. Canalis, W. Kurz: Acta Mater., 49 (2001) 1051

[12] Dye, et al. Met. Trans., 32A, (2001) 